\title{
BEHAVIOUR OF THE PANDEMIC H1N1 INFLUENZA VIRUS in Andalusia, Spain, at the onset of the 2009-10 SEASON
}

\author{
J M Mayoral Cortés1, L Puell Gómez (luz.puell.ext@juntadeandalucia.es)1, E Pérez Morilla', V Gallardo García1, \\ E Duran Pla ${ }^{1}$, J C Fernandez Merino ${ }^{1}$, J Guillén Enriquez ${ }^{1}$, J C Carmona ${ }^{1}$, G Andérica ${ }^{1}$, I Mateos ${ }^{1}$, J M Navarro Marī $^{2}$, \\ M Pérez Ruiz'2, A Daponte ${ }^{3}$ \\ 1. Epidemiology Department, Regional Ministry of Health, Andalusian Regional Government, Spain \\ 2. Influenza Reference Laboratory, Virgen de las Nieves Hospital, Granada, Spain \\ 3. Public Health and Health Protection Area, Andalusian Public Health School, Granada, Spain
}

This article was published on 10 December 2009.

Citation style for this article: Mayoral Cortés JM, Puell Gómez L, Pérez Morilla E, Gallardo García V, Duran Pla E, Fernandez Merino JC, Guillén Enriquez J, Carmona JC, Andérica G, Mateos I, Navarro Mari JM, Pérez Ruiz M, Daponte A. Behaviour of the pandemic H1N1 influenza virus in Andalusia, Spain, at the onset of the 2009-10 season. Euro Surveill. 2009;14(49):pii=19433. Available online: http://www.eurosurveillance.org/ViewArticle.aspx?ArticleId=19433

In Andalusia, Spain, the pandemic influenza A(H1N1)v virus has spread throughout the community, being the dominant influenza strain in the season so far. The current objective of the Andalusia Health Service is focussed on the mitigation of the health and social impact by appropriate care of the patients at home or in health centres. The 2009-10 seasonal influenza epidemic started early compared with to previous seasons. This article analyses the influenza A(H1N1)v situation in Andalusia until the week 39/2009.

\section{Introduction}

In Spain, first suspected cases of pandemic H1N1 influenza were notified on 26 April 2009. Starting with these first cases, an epidemic outbreak of a holomiantic nature was seen in Andalusia, with the primary cases in students who had travelled to Mexico and secondary cases in their families. There were 44 confirmed cases in this first epidemic wave until 5 May 2009. The average age of the cases was 24 years (range: 14-55 years). In 42 of them, the main symptoms were fever and cough, and 18 also had diarrhoea. All of them had mild clinical signs without complications [1].

During the first days of the outbreak, contingency plans were set up based on epidemiological surveillance, and outbreak control measures were adopted through early alert and rapid response systems. Protocols integrated the activities of the public health services, healthcare services, and the influenza reference laboratories [2]. The objective was initially to slow down the propagation of infection by identifying cases according to clinical and epidemiological criteria, reporting the first generation imported cases, their treatment, the measures adopted to prevent secondary cases and outbreaks, with an active search for any contacts. As a preventive measure, cases and contacts received treatment with oseltamivir with the recommendation to remain at home.

The declaration of pandemic phase 6 by the World Health Organization (WHO) on 11 June 2009 [3] indicated that it was no longer feasible to stop the spread of the new influenza virus. Since then, the epidemiological surveillance strategies have been aimed at defining scenarios that could aid healthcare services to respond to this emergency in order to reduce transmission and the number of affected people, and to identify and protect the most vulnerable population groups.

\section{Surveillance of influenza in Andalusia}

The epidemiological and virological surveillance of influenza in Andalusia is carried out through the Medical Sentinel Network of the Andalusian Epidemiological Surveillance System (SVEA), which consists of 128 sentinel physicians chosen according to population distribution, who are based in primary healthcare centres and cover 170,668 inhabitants (2.08\% of the Andalusian population). The influenza reference laboratory, located at the 'Virgen de las Nieves' hospital in Granada, is part of this network.

The surveillance of severe cases is undertaken through the SVEA, by means of individualised notification of the cases admitted to the public hospitals of Andalusia. Information about the use of emergency services was also collected from the computerised emergency records of public hospitals.

A case of influenza was defined as established by the European Centre for Disease Prevention and Control (ECDC) [4]. The presence of influenza $\mathrm{A}(\mathrm{H} 1 \mathrm{~N} 1)$ v was confirmed by realtime PCR carried out with SW H1 forward and SW $\mathrm{H} 1$ reverse primers and Taqman SW $\mathrm{H} 1$ probe targeted at the $\mathrm{H} 1$ gene of this virus, as recommended [5].

Characteristics of pandemic H1N1 influenza cases in Andalusia

After the first pandemic wave in April and May 2009, the influenza activity in Andalusia decreased before the summer. New cases were seen in week 28 (beginning 6 July) and increased until week 39 (beginning 21 September), when the registered influenza incidence reached 147 cases per 100,000 inhabitants (Figure 1).

In weeks 38 and 39/2009, the incidence was higher than the epidemic threshold, established as 64.1 cases per 100,000 . That implies a widespread dissemination of influenza within the population, two months ahead of the usual period for seasonal influenza. The increased influenza activity in this period is associated with a widespread escalation of the circulation of the 
influenza $A(H 1 N 1) v$ virus. Since week 28 , all circulating influenza viruses have been sub-typed and identified as influenza $A(H 1 N 1)$ v (see Figure 1).

The cumulative incidence rate for influenza until week 39 week was 643 cases per 100,000 inhabitants. In that week the highest rates were registered in the age group of 5-14 year-olds with 132 cases per 100,000 , followed by the under five year-olds with 28 cases per 100,000 . The incidence rate for those over 64 years of age was six cases per 100,000. Almost all cases showed mild symptoms lasting for a few days and responded to antipyretic

F I G U R E 1

Weekly influenza incidence rate and isolated influenza viruses, Andalusia, 2008-9 and 2009-10 seasons

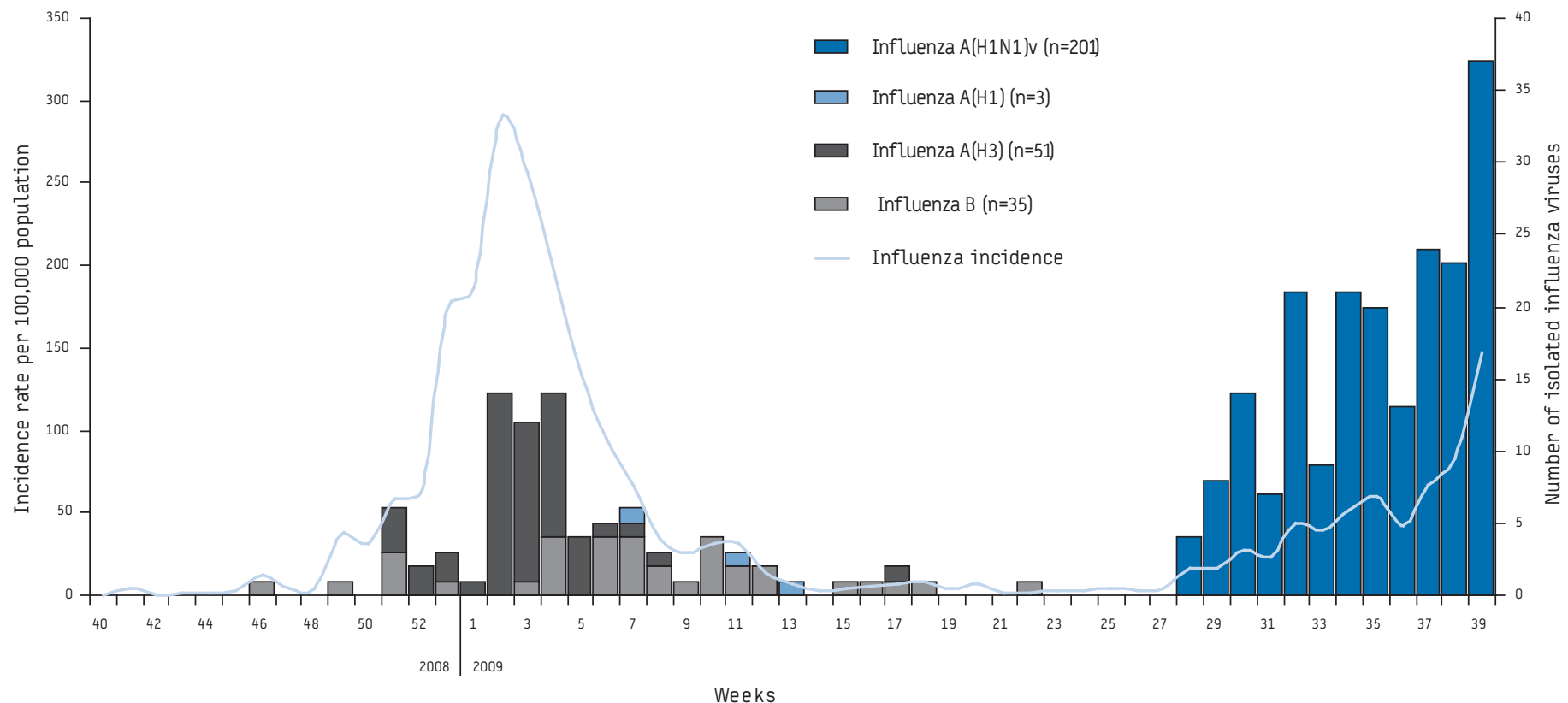

T A B L E

Characteristics of severe cases of influenza A(H1N1)v, Andalusia, weeks 17-39/2009

\begin{tabular}{|c|c|c|c|}
\hline & All hospitalised cases & Hospitalised cases $<15$ years old & Cases admitted to intensive care unit \\
\hline Number of cases & 311 & 41 & 28 \\
\hline Age (years) & $\begin{array}{l}\text { Mean: } 35.05 \\
\text { Median: } 32 \\
\text { Range: } 2-90\end{array}$ & $\begin{array}{c}\text { Mean: } 8.56 \\
\text { Median: } 9 \\
\text { Range: } 2-15\end{array}$ & $\begin{array}{c}\text { Mean: } 35.05 \\
\text { Median: } 33.5 \\
\text { Range: 2-77 }\end{array}$ \\
\hline Sex & $\begin{array}{l}\text { Male: } 129(41.5 \%) \\
\text { Female: } 182(58.5 \%)\end{array}$ & Male: 26 (63.4\%) Female: 15 (36.6\%) & $\begin{array}{c}\text { Male: } 8(28.6 \%) \\
\text { Female: } 20(71.4 \%)\end{array}$ \\
\hline Risk factors & $\mathrm{N}$ & $\mathbf{N}$ & $\mathrm{N}$ \\
\hline Asthma & 21 & 4 & 2 \\
\hline Cancer & 10 & 1 & 1 \\
\hline Cardiopathy & 24 & 2 & 0 \\
\hline Diabetes & 18 & 0 & 4 \\
\hline Chronic hepatic disease & 1 & 1 & 0 \\
\hline Active immunodeficiency & 17 & 2 & 2 \\
\hline Obesity (body mass index $\geq 40$ ) & 8 & 1 & 1 \\
\hline Chronic respiratory disease & 31 & 5 & 7 \\
\hline Convulsive disorders & 4 & 1 & 0 \\
\hline Renal failure & 2 & 1 & 2 \\
\hline Other metabolic diseases & 2 & 2 & 1 \\
\hline Other risk factors & 26 & 4 & 2 \\
\hline No risk factors & 3 & 0 & 1 \\
\hline No information & $171(55 \%)$ & $22(53.7 \%)$ & $12(43 \%)$ \\
\hline
\end{tabular}


treatment. The most frequent symptoms were fever and cough in $94 \%$ and $88 \%$ of the cases, respectively.

In the study period, 311 of the confirmed cases notified in Andalusia were severe and required hospitalisation. Of those, 28 (9\%) were admitted to intensive care units (ICUs). The hospitalisation rate for influenza was 3.7 per 100,000 inhabitants. Males represented $41 \%$ of the hospitalised cases, and $59 \%$ were female, a male/female ratio of 0.69. The age of the hospitalised cases ranged between 2 and 86 years, and $92 \%$ were under 65 years old. The average age of the cases admitted to ICUs was 38 years, with a median age of 35 years.

The most frequently registered complication during the course of the disease in severely ill patients was primary viral pneumonia, in 120 cases (39\%). About 75\% of them were 15 to 59 years of age.

For 137 of the 311 hospitalised cases (44\%), information on risk factors was recorded (see Table). Main risk factors were: prior pulmonary pathology (especially asthma or chronic obstructive pulmonary disease) in 38\% of them, a history of cardiovascular disease (18\%), immunodeficiency (12\%), diabetes (13\%), cancer (7\%), morbid obesity (6\%), and convulsive disorders (3\%).

Forty-one of the 311 hospitalised cases were under 15 years of age. Information on risk factors was recorded for 19 of them. Fifteen $(80 \%)$ presented at least one risk factor (mainly asthma and other chronic pulmonary diseases).

Of the 28 cases admitted to ICUs (including adults and children), information on risk factors was obtained for 20 cases (Table 1 ).
The most common factors were prior pulmonary pathology (chronic respiratory disease or asthma) in eight cases and diabetes in four cases. One case did not present any risk factor.

In the same period, 13 deaths due to influenza $\mathrm{A}(\mathrm{H} 1 \mathrm{~N} 1) \mathrm{v}$ were registered in Andalusia. The estimated death rate was $0.02 \%$. The average age of death was 44.3 years (range: 985 years). Information about risk factors was recorded in 10 of them. They were prior pulmonary pathology (especially chronic obstructive pulmonary disease), diabetes, morbid obesity (body mass index $\geq 40$ ), renal failure, convulsive disorders and cardiopathy.

For 75 of all hospitalised cases, we had information on the time from beginning of symptoms to start of treatment. The median time was three days (range 0-24 days). This delay increased with the severity of cases: a median of three days for the 66 hospitalised, and of four days for the nine cases admitted to ICUs.

The impact of the H1N1 influenza pandemic on the health services in Andalusia was most obvious at the beginning, between weeks 17 (beginning 20 April) and 21/2009. Attendance of hospital emergency departments peaked during this period (Figure 2). This peak in emergencies represented the alarm the first cases of pandemic H1N1 influenza caused in the population and did not reflect the number of notified cases during this outbreak. The containment measures undertaken, together with environmental factors (increased temperatures), and a reduction in the flow of travellers returning from Mexico, contributed to the control of the first phase of the outbreak. From week 22 to week 39/2009, the frequency of emergencies was similar to that observed in the

\section{F I G U R E 2}

Influenza incidence rate and hospital emergencies in Andalusia, 2005-2009

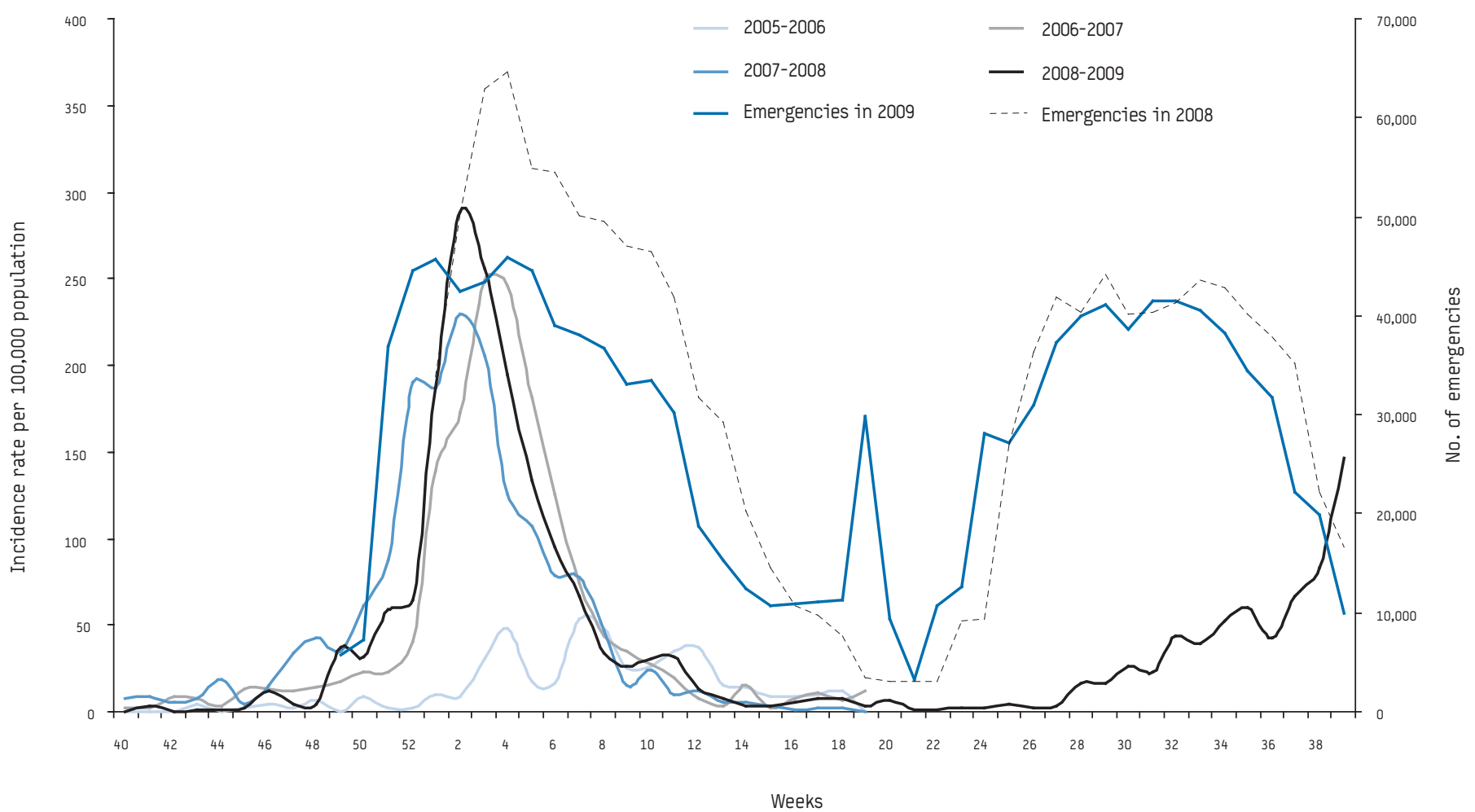


previous year, despite the increase in the incidence of influenza that took place after week 28.

\section{Conclusions}

Most cases of influenza caused by the pandemic influenza $A(H 1 N 1) v$ virus presented with a mild clinical picture similar to seasonal influenza. The majority of cases occurred in children of school age and in adults under 65 years of age, with the highest frequency of severe and fatal cases found in young adults. A significant proportion of those presented risk factors such as chronic pulmonary pathologies, cardiopathy, diabetes and morbid obesity. Similar results were observed in rest of Spain in the same period $[1,2]$. It was observed that a delay in the start of treatment increased the severity of the cases.

\section{References}

1. Ministry of Health and Social Policy, Spain. [Epidemiological surveillance of the serious human case of pandemic H1N1 influenza 2009 in Spain]. [Article in Spanish]. October 2009. Available from: http://www.msps.es/profesionales/ saludPublica/gripeA/docs/Informe_Situacion_240909.pdf

2. Ministry of Health and Social Policy, Spain. [Human cases of the pandemic H1N1 virus 2009. Descriptive analysis of the fatalities in Spain 2009]. [Article in Spanish]. Spetember 2009. http://www.msps.es/profesionales/saludPublica/ gripeA/docs/informacionFallecidosH1N1090924.pdf

3. Chancellery of Andalucia. [Preparation and response ahead of the influenza pandemic]. [In Spanish]. Available from: http://www.juntadeandalucia.es/ salud/sites/csalud/contenidos/Informacion_General/p_4_p_6_gripe_porcina/ preparacion_respuesta?perfil=org

4. World Health Organization. World now at the start of 2009 influenza pandemic. Statement to the press by WHO Director-General Dr Margaret Chan. Geneva: WHO; 2009. Available from: http://www.who.int/mediacentre/ news/statements/2009/h1n1_pandemic_phase6_20090611/es/index.html

5. European Commission. Commission Decision of 30 April 2009 amending Decision 2002/253/EC laying down case definitions for reporting communicable diseases to the Community network under Decision No 2119/98/EC of the European Parliament and of the Council. 1 May 2009. Official Journal of the European Union. Available from: http://eurlex.europa.eu/LexUriServ/LexUriServ.do?uri= 0J:L:2009:110:0058:0059:EN:PDF

6. World Health Organization. 30 April 2009, posting date. CDC protocol of real-time RT-PCR for Influenza A H1N1. 28 April 2009. Revision 1. 30 Apri 2009. Geneva: WHO; 2009. Available at: http://www.who.int/csr/resources/ publications/swineflu/CDCRealtimeRTPCR_SwineH1Assay-2009_20090430.pdf 